\title{
Referências culturais religiosas no turismo de Foz do Iguaçu: discursos, representações e sentidos
}

\author{
Culturally religious references in Foz do Iguaçu tourism: discourses, representations and meanings \\ Referencias culturales religiosas en el turismo de Foz do Iguazu: discursos, representaciones y sentidos
}

Samuel Klauck

Universidade Estadual do Oeste do Paraná (UNIOESTE),

DOI: https://doi.org/10.18472/cvt.21n1.2021.1736

Redalyc: http://www.redalyc.org/articulo.oa?

Brasil

id $=115466307003$

samuelk98@msn.com

Recepción: 01 Junio 2019

Aprobación: 10 Febrero 2021

\section{Resumo:}

O artigo analisa a exploração turística de referências culturais religiosas em Foz do Iguaçu. Analisa discursos, representações e sentidos empregados na ativação dessas referências. Objetiva: compreender e analisar a constituição das representações em torno dessas referências culturais religiosas e sua ativação pelo turismo; historicizar o processo de constituição dessa exploração turística; dialogar com os sentidos teóricos conceituais que permitem compreender o desenvolvimento do turismo de referências culturais religiosas na cidade. Segue os preceitos metodológicos de base bibliográfica, ancorados na compreensão dos discursos, representações e a ativação dos sentidos e significados associados às referências culturais religiosas. Traz como resultados: breve decurso histórico do turismo na cidade; reflete sobre o aumento do número de visitantes à região e o fomento de novos pontos de visitação vinculados aos atrativos históricos culturais; percebe a divulgação das referências culturais por meio de discursos e representações produzidas pelo poder público municipal e pelo mercado turístico

Palavras-Chave: Foz do Iguaçu, Referências Culturais Religiosas, Turismo.

\section{Abstract:}

This paper analyzes the touristic exploration of culturally religious references in Foz do Iguaçu. It analyses discourses, representations and meanings employed in the activation of these references. It aims to: understand and analyse the constitution of representations around these culturally religious references and their activation by tourism; to historicize the constitution process of such touristic exploration; to dialogue with the theoretical and conceptual meanings that enable to understand the development of culturally religious references in the city. It follows the methodological principles of bibliographic basis, grounded in the understanding of discourses, representations and the activation of meanings and significations associated with the culturally religious references. It brings the following results: a brief historical course of tourism in the city; it reflects about the rise of visitor numbers towards the region and the foment of new visiting points related to the historical cultural attractions; it perceives the promotion of the cultural references by the means of discourses and representations produced by the municipal local power and by the touristic market.

KEYWORDS: Foz do Iguaçu, Culturally Religious References, Tourism.

\section{Resumen:}

El artículo analiza la exploración turística de referencias culturales religiosas en Foz de Iguazú. Analiza discursos, representaciones y sentidos empleados en la activación de esas referencias. Objetiva: comprender y analizar la constitución de las representaciones en torno a esas referencias culturales religiosas y su activación por el turismo; historicizar el proceso de constitución de esa explotación turística; dialogar con los sentidos teóricos conceptuales que permiten comprender el desarrollo del turismo de referencias culturales religiosas en la ciudad. Sigue los preceptos metodológicos de base bibliográfica, anclados en la comprensión de los discursos, representaciones y la activación de los sentidos y significados asociados a las referencias culturales religiosas. Trae como resultados: breve desarrollo histórico del turismo en la ciudad; reflexiona sobre el aumento del número de visitantes a la región y el fomento de nuevos puntos de visitación vinculados a los atractivos históricos culturales; percibe la divulgación de las referencias culturales por medio de discursos y representaciones producidas por el poder público municipal y el mercado turístico. Palabras Clave: Foz de Iguazú, Referencias Culturales Religiosas, Turismo. 


\section{INTRODUÇÃO}

As análises deste artigo surgem associadas a percepção de que Foz do Iguaçu, a terceira cidade turística brasileira que mais atraiu estrangeiros em 2017, passou por uma progressiva valorização e expansão dos pontos de visitação ligados ao turismo histórico cultural. A partir dos anos de 1990, o poder público municipal, por meio da Secretaria Municipal de Turismo, inventariou e divulgou pontos de referência cultural presentes na cidade.

O setor privado, principalmente agências e restaurantes, também se dedicaram a inserir junto aos três principais atrativos - Cataratas do Iguaçu, Usina Hidrelétrica de Itaipu Binacional e o roteiro de compras em Ciudad del Este - o serviço de alimentação e de guia aos espaços que remetem às referências histórico culturais da cidade.

Progressiva e conjuntamente, percebe-se a elaboração de estratégias de ampliação dessa oferta, por meio da divulgação e da profissionalização de setores envolvidos diretamente com o turismo histórico e cultural. Destaca-se o empenho do poder público em produzir imagens, narrativas e discursos acerca da história, da cultura, dos espaços e atrativos a eles referidos. Ao mesmo tempo em um empreendimento, até então inédito na região, o City Tour, é lançado pela Loumar Turismo (LOUMAR), em 2011, tendo como foco os pontos turísticos, as curiosidades e a formação cultural da cidade.

Tanto o poder público como a iniciativa do mercado turístico lançam mão da divulgação, da oferta e da comercialização de pontos de referências histórico-culturais. A exemplo disso, cita-se que a página da Secretaria de Turismo apresenta 12 atrativos histórico-culturais, que são: Igreja Matriz; Catedral Nossa Senhora de Guadalupe; Mesquita; Marco das Três Fronteiras; Outras Edificações Históricas; Ecomuseu; Bibliotecas; Centro Cultural / Casa da Cultura; CEAEC - Centro de Altos Estudos da Conscienciologia; Feiras e Mercados; Artesanato e Templo Budista. Esses mesmos pontos podem ser encontrados ofertados por agências de turismo, bem como é possível identificar que fazem parte do rol de destaques divulgados na rede mundial de computadores.

Dentre as referências culturais destacadas, tanto pelo poder público como pelo mercado turístico, o recorte das análises se dará nas religiosas, que são: a Igreja Católica São João Batista, presente na cidade desde 1924; a Catedral Nossa Senhora de Guadalupe, em fase de construção; a Mesquita Omar Ibn Al-Khattab, inaugurada em 1983; o Templo Budista Tien Chien, inaugurado pela comunidade chinesa desta região em 1996 e a Cenografia Arquitetônica das Reduções Jesuíticas, construída no Marco das Três Fronteiras em 2016.

As reflexões que seguem pautam-se no objetivo central de compreender e analisar como se constituem as representações em torno destas referências culturais religiosas e como são ativadas pelo turismo. Como desdobramento, intenta historicizar brevemente o processo de constituição dessa exploração e dialogar com os sentidos teóricos conceituais que permitem compreender o desenvolvimento do turismo de referências culturais religiosas em Foz do Iguaçu.

Por sua vez, enquanto princípios de ordenamento das reflexões, constituem pontos de ancoragem os preceitos de compreensão da constituição de discursos e a percepção da formação de representações em torno das referências culturais religiosas. As análises seguem associando estes preceitos ao mercado turístico e ao poder público como agentes da ativação destas referências, difundidas e exploradas como pontos de visitação no espaço de Foz do Iguaçu.

\section{Material e Método}

A história de Foz do Iguaçu, município situado no Oeste do Paraná, limítrofe com dois países (Argentina e Paraguai), respectivamente através dos rios Iguaçu e Paraná, é marcada pela presença de transeuntes e representações produzidas por eles no processo histórico que se estende desde o final do século XVI até o presente. Entre os destaques despontam as características atrativas do local, como as destacadas pelo espanhol 
Álvar Núñez Cabeza de Vaca (1999), em seu relato de 1542 sobre a descoberta das quedas do Rio Iguaçu, hoje reconhecidas como as Cataratas do Iguaçu. Apesar do silêncio ou ausências de narrativas sobre o local no período colonial brasileiro, Foz do Iguaçu e região reaparecem a partir do século XIX na descrição de ponto de referência de escoamento de madeira e erva mate pelo rio Paraná (Gregory, 2012), como ponto avançado de segurança nacional (Santos e Cury, 2015), como espaço produtivo (Roseira, 2006), pela natureza exuberante comumente acionada pelos discursos do mercado turístico, entre tantos outros.

O título do livro de A Fronteira Como Destino de Viagem (Myskiw, 2011) bem poderia ser em síntese a tonalidade das representações sobre a cidade e a região do seu entorno. Contudo, é a partir da metáfora de viagem ou do viajar que nasce o foco destas análises, pois, desde o início do século $\mathrm{XX}$, esse espaço se destaca pela atração de pessoas, que propositadamente se deslocam com o objetivo de visitar/conhecer as quedas do Rio Iguaçu.

A gênese da atração de viajantes está relacionada à história do turismo nessa região. Ottília Schimmelpfeng, filha do primeiro prefeito da cidade, Jorge Schimmelpfeng, faz destaque a essa situação quando aponta a presença de vapores argentinos nessa região nas décadas de 1930 e 1940. Em suas palavras:

Logo vieram os barcos de passageiros movidos à vapor - os vapores, como se dizia, dotados de conforto, já visando a exploração do turismo que se iniciava em Puerto Aguirre, ponto de partida para as Cataratas. Estes faziam transporte misto, conduzindo a carga de erva-mate nos poróes. (Schimmelpfeng, 2002, p.46. Grifo da autora)

A mesma situação pode ser corroborada com a história da hotelaria na cidade. A memória descrita por Otíllia, novamente nos serve como referência para perceber um pouco desses antecedentes. Segundo ela, a rede de hospedagem e/ou acomodaçóes iniciou-se associada aos visitantes que vinham à região. Segundo Otília,

Foi no ano de 1915, que veio despontar a atividade turística em Foz do Iguaçu. Quando, então, se instalou o Hotel Brasil, de propriedade de Frederico Engel, com filial no local das quedas. Eram pequenos estabelecimentos em condições precárias, porém, atendiam o seu objetivo: acolher o visitante e conduzi-lo às cataratas. (Schimmelpfeng, 2002, p. 23. Grifo da autora)

É notório que as belezas naturais das Cataratas do Iguaçu, conforme as representações valorativas empregadas na divulgação deste ponto de visitação, tenham sido e permaneçam como o principal chamariz no sentido da atração dos turistas e transeuntes que passam pela região. Pode-se aferir, com certa naturalidade que a cidade, ou melhor, Foz do Iguaçu, é acionada discursivamente ou lembrada por um grande contingente populacional, tanto no Brasil como no mundo, pela referência às Cataratas do Iguaçu.

Essa marca é tão importante no sentido de produzir uma imagem sobre e a partir da cidade, que os números em torno dela mostram esse destaque. Se os dados que antecedem os grandes marcos estruturais da cidade, como a abertura do Aeroporto, em 1935 (Farias e Monges, 2006), a inauguração da BR-277, em 1969, a construção de duas pontes internacionais, a da Amizade, em 1965 e a da Fraternidade, em 1984 (Catta, 2002), são bastante tímidos, não é o que se percebe a partir dos anos de 1990.

Conforme dados compilados pela Secretaria Municipal de Turismo, no seu Inventário Turístico, em 1983, o Parque Nacional do Iguaçu - local do principal ponto turístico da cidade - recebeu 420.778 turistas, tanto brasileiros quanto estrangeiros. Dez anos depois, esse número subiu para 868.748 visitantes. Após vários anos de oscilação na casa do 600, 700 e 800 mil turistas, a partir de 2007 esse número sempre esteve muito acima de 1 milhão de visitantes (Foz do Iguaçu, 2017). Esses dados corroboram os argumentos de Cardin (2010) e Henz e Gonçalves (2016), que apontam a profissionalização do turismo e o planejamento integrados como parte desse processo.

Números de 2017 confirmam esse crescimento de visitantes que adentraram no Parque Nacional do Iguaçu. Segundo o portal G1 (2018a), da Rede Globo, esse atrativo natural recebeu 1.788.922 visitantes de 166 nacionalidades. As informações quantitativas reforçam os dados iniciais destacados anteriormente do grande número de visitantes, divididos entre várias regiões do mundo. Além disso, a mesma reportagem 
permite compreender o aumento progressivo de visitantes desde 1999. Destaca, com poucas exceções, um crescimento permanente de 772.287 visitantes em 1999, até alcançar o dado de 2017, apontado acima.

Como nos lembra Krippendorf (2009), o turismo apresenta essa capacidade de movimentação de pessoas. E, como desdobramento disso, cabe destacar, que há a possibilidade de interação entre a comunidade receptora e o visitante. Esta lembrança é fundamental, pois, apesar do atrativo ser natural, localizado fora do centro urbano da cidade, dentro de um Parque Nacional, o qual lhe confere significado ao ser reconhecido com Patrimônio Natural da Humanidade, atribuído pela Unesco em 1986, é a cidade e a região que acolhe esse contingente de turistas.

Por sua vez, os números apresentados não refletem necessariamente que todos os turistas interajam com a população local, ou como se preconiza, que consumam além da natureza, as referências culturais da cidade. Cabe relembrar que, além das Cataratas, outros dois atrativos são importantes nesse mercado e que, de alguma forma, atraem parcela desse contingente, que são: a visitação à Usina Hidrelétrica de Itaipu e o fazer compras em Ciudad del Este, no Paraguai.

Contudo, desde meados da década de 1990, procura-se associar aos três atrativos, a cidade e suas referências culturais. Encontram-se indicativos dessa intenção nos discursos e representações produzidos acerca de algumas manifestações enunciados pelo poder público municipal, geralmente pela Secretaria Municipal de Turismo, órgãos do turismo estadual e empresas vinculadas a esse setor. Destacamos, dentre eles, o discurso de enaltecimento da diversidade populacional, em dar ênfase à presença de mais de 7 dezenas de nacionalidades nesse espaço.

De fato, dados como os apresentados nos sítios eletrônicos da prefeitura que indicam a presença de aproximadamente 80 nacionalidades (Foz do Iguaçu, 2019a), como trabalhos científicos que reconhecem a presença de um variado contingente de grupos neste espaço (Silva, 2008; Oliveira, 2012), corroboram os números. Mas, ao reduzirmos a percepção às representações que produzem marcas e significados evidentes neste espaço, o argumento da diversidade não se sustenta. Ou seja, há a diversidade, mas a maioria desta população não consegue se reconhecer internamente como grupo ou ser reconhecido externamente como tal.

São exceções dessa situação grupos numericamente expressivos, como árabes, paraguaios e asiáticos, que de alguma forma imprimiram neste espaço referências materiais e imateriais de sua cultura. A partir das autoras Silva (2008) e Oliveira (2012) e da observação empírica, pode-se definir que os primeiros se estabelecem a partir dos anos de 1950, como comerciantes. Apesar de nomeados como árabes, é notório que o grande contingente é formado por imigrantes libaneses, sírios e palestinos, atraídos à região pelo crescimento econômico advindo da construção da usina de Itaipu e a abertura uma zona comercial em Ciudad del Este no Paraguai. Por sua vez, os paraguaios se inserem neste espaço em dois momentos principais, seja como exilados políticos do regime de Alfredo Stroessner ou como resultado das acomodaçóes econômicas trazidas nos anos de 1980 nessa região. Já entre asiáticos destacam-se os taiwaneses, comumente unificados no cotidiano local como chineses. Contudo, as observações empíricas, a partir da nomeação de restaurantes, também permitem identificar japoneses e coreanos atraídos principalmente pelas potencialidades econômicas.

A tentativa de associar a cidade aos grupos que aqui transitam ou se estabeleceram é declaradamente uma ação deliberada da lógica do mercado do turismo. Pois, se há quase dois milhóes de turistas visitando as Cataratas do Iguaçu durante um ano, por que não criar ferramentas e estratégias para que estes permaneçam e consumam mais a cidade e a região? Esforços nesse sentido sempre existiram e alguns casos específicos lograram êxitos importantes, como as churrascarias tipificadas como gaúchas e espaços com apresentações culturais.

Contudo, ao acessarmos as informações da Secretaria Municipal de Turismo em seu website (http:// www.pmfi.pr.gov.br/turismo/), e, nesta, a aba Atrativos Turísticos e, em seguida, a de atrativos HistóricoCulturais, são destacados 12 pontos, que remetem de forma direta às referências culturais da cidade já destacados acima. 
Os locais elencados demonstram parcialmente as referências de uma diversidade populacional que, por sua vez, se traduz em diversidade cultural. É uma percepção parcial, pois não abarca a complexa formação histórica desta constituição. Mas, de maneira geral, trazem elementos históricos materiais da formação da cidade, como prédios e construções antigas, aspectos da migração - templo religioso muçulmano e budista e a comunidade do CEAEC, espaços de memória - como o museu e espaço de cultura. Da mesma forma, esses mesmos locais trazem em si referências culturais que são imateriais, como a culinária e a religiosidade.

Outro aspecto evidenciado na lista de referências histórico-culturais é o religioso. Dos pontos indicados 4 são templos ligados a comunidades religiosas: duas católicas, uma muçulmana e outra budista. Indiretamente, o Marco das Três Fronteira, após a revitalização que implantou naquele espaço uma cenografia arquitetônica de uma Redução Jesuítica Guarani, também pode ser compreendido pelo aspecto religioso, ao remeter a ativação da memória desta experiência na América do Sul. Essas referências têm seu aspecto material explorado pelo turismo, ou seja, é sua arquitetura que se destaca e pode ser encontrada na divulgação desses espaços, comumente associados a imagens das construções.

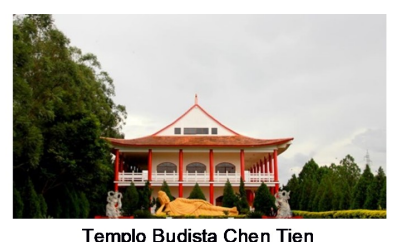

Templo Budista Chen Tien

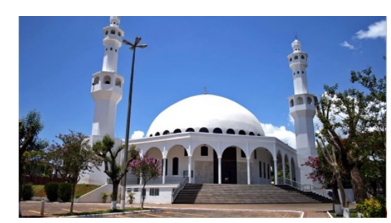

Mesquita Sunita Omar Ibn Al-Khattab

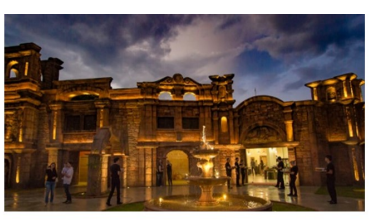

Pórtico no Marco das Três Fronteiras

\section{FIGURA 1}

Imagens da Divulgação dos Passeios Oferecidos em Foz do Iguaçu

Fonte: LOUMAR (2019).

É dentro desta contextualização, que permeia um pouco da formação da cidade e como o turismo se desenvolveu, que o foco das análises passa a ser os discursos e as representações do mercado turístico acerca das referências religiosas presentes na cidade.

\section{Resultados e Discussão}

A referência à pluralidade cultural desse espaço encontra suas bases de sustentação em dois princípios: a realidade empírica percebida pelos transeuntes e por meio da fixação de representações. A primeira situação é encontrada no fazer cotidiano da cidade, tanto dos moradores, como dos turistas: a diversidade aflora nos encontros e desencontros linguísticos, na oferta de comidas típicas, nas maneiras de vestir, nas referências religiosas, em marcos simbólicos, como construções, entre outros. Já a segunda situação ocupa um lugar mais complexo do que a suposta realidade aparenta ser: são os discursos produzidos para fixar uma determinada visão acerca da cidade e suas referências culturais. Será este princípio de apresentação dos sentidos de pluralidade que dará fundamentação aos nossos argumentos.

Cabe destacar que se compreende o discurso na acepção direta da palavra, conforme proposto por Dominique Maingueneau, ou seja, é o ato de enunciar algo a partir de uma intencionalidade, para destinatários pré-definidos, para alcançar resultados previamente esperados (Maingueneau, 1989, p. 34). A definição do autor permite que olhemos para os discursos que enaltecem a diversidade e a entendamos como um ato pensado e intencional. Aqui é possível aproximar nossas análises desta acepção.

Percebe-se que a diversidade religiosa é manifesta e descrita nos registros oficiais. Segundo dados do Instituto Brasileiro de Geografia e Estatística (IBGE, 2010), Foz do Iguaçu apresenta uma diversidade religiosa, seja distribuída entre seguidores de credos cristãos, ao islamismo, budismo, religiões afrodescendentes, dentre outros. 
Os dados numéricos da definição religiosa do Censo de 2010 refletem o processo histórico da formação da cidade. Dentre os 256.088 habitantes, como grupo majoritário, destacam-se os católicos com 149.959 e esse contingente de cristãos é seguido pelos que se vinculam aos evangélicos, com 70.420 (IBGE, 2010). Aqui se encontra a paridade com as estatísticas nacionais que colocam os grupos religiosos mencionados como os principais grupos religiosos do Brasil. Contudo, a partir dos anos de 1980, conforme destacado por Silva (2008), a região passa a receber um grande contingente de pessoas do Oriente Médio e da Ásia. Estes novos imigrantes trazem e reproduzem nesse cotidiano suas referências religiosas. Essa evidência corrobora os 5.599 muçulmanos e 1.067 budistas indicados no Censo do IBGE (2010). É importante destacar que entre os muçulmanos evidenciam-se subgrupos divididos em sunitas, xiitas e drusos. Por sua vez, a própria característica do budismo, não permite unificar todos em torno da mesma linha religiosa, quando se considera a diversidade de grupos oriundos desta crença.

Os dados acima podem ser corroborados por meio de busca na rede mundial de computadores, usando a frase "diversidade religiosa de Foz do Iguaçu". Os resultados destacam imagens associadas ao mercado turístico, como o Templo Budista, a Mesquita Muçulmana e a Igreja Católica São João Batista. Da mesma forma, ao acionarmos o portal da Secretaria Municipal de Turismo essas referências também se destacam (Foz do Iguaçu, 2019b). Também, apoiam as informações anteriores os pontos de referências culturais religiosos em empresas que prestam serviços turísticos na cidade, tais como pode ser evidenciado na divulgação eletrônica da LOUMAR (2019).

As análises anteriores nos levam a discussão das formas de construção destes discursos, compreendidos como representações, como são praticados e apropriados, na acepção de Roger Chartier, pelo mercado turístico e associados como referências de diversidade desse espaço. Entende-se como fundamental definir os significados das terminologias. $\mathrm{O}$ autor em tela é fundamental para a discussão do conceito de representação. Segundo ele

As representações do mundo social assim construídas, embora aspirem à universalidade de um diagnóstico fundado na razão, sempre são determinadas pelos interesses do grupo que as forjam. Daí, para cada caso, o necessário relacionamento dos discursos proferidos com a posição de quem os utiliza. (Chartier, 1990, p. 17).

Ainda segundo o autor

As lutas de representações têm tanta importância como as lutas económicas para compreender os mecanismos pelos quais um grupo impõe, ou tenta impor, a sua concepção do mundo social, os valores que são os seus e o seu domínio. (Chartier, 1990, p. 17).

Os excertos corroboram a análise de constituição de discursos produzidos para enfatizar determinadas características presentes na diversidade cultural de Foz do Iguaçu ao interesse de grupos vinculados ao mercado do turismo. Além disso, exibe a lógica e os porquês em torno da exposição das referências religiosas da cidade. Neste caso, é preciso recuperar os dados do número de visitantes que Foz do Iguaçu recebeu e continua recebendo. Os números são de potenciais consumidores da história, da memória e de referências culturais desse espaço. Portanto, no complexo jogo do mercado, que podem ser tomadas como lutas de representações, os sentidos, significados e a exploração das referências culturais passam a ser estabelecidos.

Esse jogo de mercado se constitui a partir das evidências que se quer produzir acerca das referências culturais religiosas da cidade. Ou seja, ancora-se em discursos que se propõem a esse fim. Novamente acionase Roger Chartier, com o intuito de perceber e compreender essa situação. Segundo ele há duas formas de se instituir representações e a primeira

[...] como dando a ver uma coisa ausente, o que supõem uma distinção radical entre aquilo que representa e aquilo que é representado; por outro, a representação como a exibição de uma presença, como apresentação pública de algo ou alguém. (Chartier, 1990, p. 20). 
$\mathrm{Na}$ realidade apresentada, destacam-se as possibilidades de acionarmos os dois sentidos apresentados pelo autor. Em primeiro lugar, nenhuma das referências apresentadas ou acionadas pelos discursos como referências culturais religiosas pelo jogo do mercado do Turismo se constituíram com esse intuito. São, sim, resultados da construção de monumentos de memória e identidade dos praticantes dessas formas de religião e religiosidade. Portanto, aquilo que é, não significa necessariamente o que é representado. Além disso, denota escolhas, pois, no universo de manifestações religiosas da cidade, outras tantas, bem como seus marcos de memória, raramente são acionados por meio dessa lógica.

Por sua vez, o segundo aspecto é comumente próprio da lógica do mercado do turismo, de fixação intencional pública de algo ou de alguém, para com isso lograr resultados econômicos. Nesse sentido, as referências culturais religiosas destacadas pelos discursos públicos, por empresas de turismo e na rede mundial de computadores, corroboram o sentido da intencionalidade de exibir uma presença. Para construir essa presença, são necessários recortes, escolhas, e produção de sentidos por meio do acionamento de discursos e práticas de valorização destes espaços.

Nesse sentido

[a representação] permite articular três modalidades da relação com o mundo social: em primeiro lugar, o trabalho de classificação e delimitação que produz as configurações intelectuais múltiplas, através das quais a realidade é contraditoriamente construída pelos diferentes grupos; seguidamente, as práticas que visam fazer reconhecer uma identidade social, exibir uma maneira própria de estar no mundo, significar simbolicamente um estatuto e uma posição; por fim, as formas institucionalizadas e objectivadas graças às quais uns "representantes" (instâncias colectivas ou pessoas singulares) marcam de forma visível e perpetuada a existência do grupo, da classe ou da comunidade. (Chartier, 1990, p. 23).

As três modalidades trazidas pelo autor correspondem a prática do turismo em Foz do Iguaçu. Em primeiro lugar, as escolhas dos pontos de visitação acionados pelas suas referências culturais, reflete a classificação produzida pela ciência estatística. Os dados do IBGE apoiam o discurso que mostra que a cidade apresenta uma diversidade religiosa e que essa classificação não reflete a diversidade absoluta de crenças religiosas, ela reflete a delimitação do como se quer representar essa realidade.

Por sua vez, a segunda modalidade traduz as disputas de identidade em torno da fixação de territórios simbólicos do sagrado. Aproximando a questão dos nossos exemplos, percebemos que os marcos de visitação - os templos católicos, a mesquita e o templo budista - representam uma imbricada luta de representações entre três grandes referências religiosas mundiais. Demonstram uma forma de reforçar a posição dos grupos e mostra como tais grupos se constituem.

Nesse aspecto, é importante ressaltar que esses três grupos religiosos são numericamente díspares e mesmo assim apresentam grande capacidade de se apresentar simbolicamente neste espaço. Desta constatação se depreende a terceira modalidade de representação social que é a capacidade individual ou coletiva de visibilidade de um grupo. Essas três modalidades de representação, de acordo com Chartier (1990), ancoramse na apropriação e na prática para alcançar determinados objetivos. Segundo ele

A apropriação, tal como a entendemos, tem por objectivo uma história social das interpretações, remetidas para as suas determinações fundamentais (que são sociais, institucionais, culturais) e inscritas nas práticas específicas que as produzem. (Chartier, 1990, p. 26).

Ocupam destaque neste excerto as determinações fundamentais, pois, quando associadas à evidência que os pontos de referência assumem nas representações turísticas da cidade, percebe-se o papel institucional do turismo e as ações práticas de mercado associado a ele. Essas análises ancoram-se na percepção das práticas, principalmente as discursivas, empregadas para se lograr os objetivos propostos para o destaque dos pontos turísticos citados. Nesse sentido, a assertiva de Chartier é elucidativa:

Daí a caracterização das práticas discursivas como produtoras de ordenamento, de afirmação de distâncias, de divisões; daí o reconhecimento das práticas de apropriação cultural como formas diferenciadas de interpretação. (Chartier, 1990, pp. 27-28). 
Aproximando a definição de práticas discursivas da nossa de reflexão, destacam-se dois pontos: primeiro, que estas procuram reforçar o discurso da diversidade cultural da cidade, e, segundo, que essa diversidade enquanto apropriação cultural presta-se ao mercado do turismo, por meio do acionamento das referências culturais que as manifestações trazem em si.

Essa questão se desdobra na compreensão da constituição dessas referências culturais. Auxilia-nos nesse processo o sociólogo Gilberto Giménez. Segundo ele

La cultura ya no se presenta ahora como "pautas de comportamiento", como en la década de 1950, sino como "pautas de significados". En esta perspectiva podemos definirla como "la organización social de significados, interiorizados de modo relativamente estable por los sujetos en forma de esquemas o de representaciones compartidas, y objetivados en formas simbólicas, todo ello en contextos históricamente específicos y socialmente estructurados". (Giménez, 2009, p. 8).

Aproximando a definição do autor da percepção das referências culturais da cidade, percebe-se que há indícios do acionamento das duas formas de compreensão de cultura. A forma de ver o outro, na acepção do identitariamente diferente, encontra consonância com a visão antropológica dos anos de 1950, de entender cultura ainda enquanto comportamento. E o mercado do turismo contribui para essa interpretação, como nos exemplos das imagens destacadas anteriormente. Em um país eminentemente católico, é plausível conjecturar que a maioria dos brasileiros, e até mesmo estrangeiros, pauta-se frente ao templo budista e à mesquita, acionando os comportamentos do grupo, seja pelas vestimentas ou ornamentação e características das construções. Da mesma forma, o Pórtico Jesuítico, com marco de memória de outro tempo, pode ser explicado pela experiência "exótica" na América do Sul.

Ainda em diálogo com Giménez, é importante destacar que a pauta de significados também se faz presente, pois, os pontos de visitação integram sentidos, construídos e reconstruídos por comunidades religiosas no esforço de manter suas formas de ser. Portanto, apesar do acionamento das referências culturais por meio do turismo comumente ocorrer por meio do comportamento, muitas vezes encontra sua explicação na dificuldade de transmitir ao visitante os significados culturais envoltos nas crenças dos grupos que produziram os pontos elencados, no tempo rápido de cada visitação.

Nessa perspectiva, novamente o sociólogo nos auxilia ao destacar as duas formas de percebermos a cultura. Diz ele que

la distinción entre "formas objetivadas" y "formas interiorizadas" de la cultura, dialécticamente relacionadas entre sí. En efecto, por una parte, los significados culturales se objetivan en forma de artefactos o comportamientos observables, llamados "formas culturales" por john B. Thompson(1998:202ss); por ejemplo, obras de arte, ritos, danzas; y por otra, se interiorizan em forma de habitus, de esquemas cognitivos o de representaciones sociales. (Giménez, 2009, pp. 8-9. Grifo do autor).

Assim, quando analisamos os pontos de visitação em destaque, percebemos que há sim a exposição das duas formas de cultura. Em primeiro lugar, a arquitetura e, eventualmente, comportamentos observados nos locais, materializados nos espaços, permitem compreender as formas objetivadas de cultura. Contudo, os espaços "exigem" comportamentos do visitante, como, por exemplo, as mulheres cobrirem a cabeça com um lenço ao adentrarem na Mesquita, ou o de respeitar a meditação do monge ou oração de um católico nos respectivos espaços. Neste caso, mesmo que superficialmente, é possível conjecturar que haja a percepção dos habitus e das representações sociais presentes nestes espaços.

Tanto as formas objetivadas como as interiorizadas de cultura constituem as referências do que chamamos de patrimônio cultural. Como nos apresenta Llorenç Prats

[...] la acepción que remite al concecpto de patrimonio cultural, entendido como todo aquello que socialmente se considera digno de conservación independientemente de su interés utilitário. Por supuesto este concepto abarca también lo que comúnmente se conoce como patrimonio natural, en la medida em que se trata de elementos y conjuntos naturales culturalmente seleccionados.

El patrimonio cultural es una invención y uma construcción social. (Prats, 1988, p. 63) 
Corrobora nossa percepção de que o patrimônio se constitui nas práticas cotidianas, historicamente significadas e que usam mecanismos de transmissão efetivos para a manutenção das referências. Ou seja, esse conjunto patrimonial não representa tão somente as culturas que ativam seu patrimônio intencionalmente e que alcançam grande evidência. Mas, todas as formas de referências culturais que produzem sentido aos grupos que as constituem. De forma que toda cultura objetivada e interiorizada assume o sentido de ser patrimônio dos que se identificam, praticam e transmitem essa cultura.

Ora, por sua vez, em uma cidade turística como Foz do Iguaçu, que percebeu a potencialidade de inserir o grande número de visitantes em outros atrativos, levou, como se percebe, à "comercialização" de referências culturais objetivas e interiorizadas de alguns grupos que integram esse espaço. Percebe-se que essa ação deliberada é uma tentativa de ativar o que acima chamamos de patrimônio cultural deste espaço. $\mathrm{Na}$ compreensão deste processo ressalta-se que o decurso não se produziu naturalmente. Nesse sentido, o que nos traz Llorenç Prats é elucidativo:

He sostenido y continúo sosteniendo que los processos de activación del patrimonio dependem fundamentalmente de los
poderes políticos. Sin embargo, estos poderes deben negociar con otros poderes fácticos y com la propia sociedade. Alrededor
de la pueste em valor de tal o cual elemento se produce precisamente el primer processo de negociación, en la medida que
existe en la sociedade uma previa puesta em valor jerarquizada de determinados elementos patrimoniales, fruto normalmente
de procesos identitarios, no necessariamente espontáneos, o no completamente espontáneos, pero que pueden comportar
um alto grado de espontaneidad y consenso prévio. (Prats, 2005, pp. 19-20)

A indicação de Prats corrobora a forma de ativação de algumas referências patrimoniais em Foz do Iguaçu. Dos discursos epidíticos - ostentosos, que enaltecem a diversidade de maneira geral, percebe-se que os processos de ativação do patrimônio seguiram estratégias que envolveram o poder público, empresas que operam o turismo e a lógica do mercado vinculado a ele. É neste momento que a hierarquização das referências patrimoniais é definida, ancorada em evidências identitárias mais expressivas, ou com capacidade de alçar maior visibilidade nesse espaço. Contudo, esses pontos apresentam outra vantagem, a do consenso prévio de apresentarem cultura objetiva e interiorizada de forma espontânea, necessária à reprodução das referências religiosas dos grupos que a integram.

Ainda nesta reflexão, o transcurso nos leva à pergunta de como ocorre o processo de ativação de um patrimônio. Novamente, Prats nos auxilia quando nos apresenta que

Este discurso se basa en unas reglas gramaticales sui generis, que simplemente recordaré, que son: la selección de elementos integrantes de la activación; la ordenación de estos elementos (como equivalente a la construcción de las frases del discurso); y la interpretación (o restricción de la polissemia de cada elemento-palavra mediante recursos diversos, desde el texto a la iluminación, o la ubicación). (Prats, 2005, p. 20. Grifos do autor)

Desta constatação que permite apoiar nossas análises sobre Foz do Iguaçu, o mesmo autor chama a atenção para o desenvolvimento do turismo, do consumo e da mídia na consolidação do processo de ativação do patrimônio cultural. Segundo ele

Por outra parte, con el dessarrollo, em las sociedades capitalistas avanzadas, del consumo de ocio y turismo (más tempo, espacio y dinero dedicado a estas actividades y, por tanto, más empresas e iniciativas al respecto) las activaciones patrimoniales han adquirido outra dimensión, han entrado abiertamente en el mercado y han pasado a evaluarse em términos de consumo (visitantes fundamentalmente, pero también merchandising y publicidade mediática), actuando éste, el consumo, como medidor tanto de la eficacia política como de la contribuición al dessarrollo o consolidación del mercado lúdico-turísticocultural. (Prats, 2005, p. 22)

Aqui, percebe-se retratado o cenário de Foz do Iguaçu. A atratividade turística das Cataratas do Iguaçu, conforme demonstrado anteriormente, gerou um crescimento progressivo e intenso do número de visitantes à cidade. Esse contingente de visitantes é visto como possível consumidor de um mercado lúdico-turísticocultural, como apontado por Prats. É dentro desse contexto que a ativação patrimonial lançará mão de discursos e construirá representações. Por sua vez, constituíram-se políticas públicas de fomento do turismo 
(Henz e Gonçalves, 2016) e que culminaram com venda das referências culturais em escala comercial e ordenada, como podemos ver no exemplo do City Tour e pacotes oferecidos por empresas de turismo, facilmente encontrados na rede mundial de computadores.

A guisa de fechamento da relação da ativação dos referenciais culturais com o turismo e o consumo, Prats, em um texto de 1988, é enfático:

Con el turismo y la televisión podemos decir, pues, que, además de nuestra própria vida cotidiana, vivimos otras dos realidades ajenas a través de los "viajes" (ya sean materiales o virtuales). Esto nos há habituado también a convertir la realidad em espectáculo, es decir a que todo (incluso la guerra y la miseria) podamos contemplarlo como espectadores, a la vez que la economía de mercado nos há acostumbrado a que todo (también la guerra y la miséria) se puede convertir en artículo de consumo (aunque sea también como espectáculo), es decir, se pueda adquirir con dinero.

[...] sobre todo, nacen um nuevo tipo de activaciones patrimoniales cuya motivación no es ya de carácter identitario, sino abertamente turístico y comercial, para lo cual, los referentes que se activan y los significados que se les confiere no responden ya a los diveros nosotros del nosotros que pueden representar las distintas versiones idiológicas de la identidade, sino, fundamentalemente, al (sin los) nosotros de los otros, es decir, la imagem externa, y frecuentemente estereotipada que se tiene de nuestra identidad (de los protagonistas) desde los centros emissores de turismo. (Prats, 1988, p. 70. Grifo do autor)

Da questão em tela é preciso retomar uma em específico, que é: de que forma os discursos e o turismo são capazes de fazer a ativação das referências culturais da cidade, em específico as vinculadas aos aspectos religiosos? Indícios dessa resposta podem ser encontrados no debate dos referentes e dos significados que cada espaço visitado permite conceber. Os pontos analisados constituem-se materialmente, no aspecto físico e arquitetônico, com espaços chamativos. Excetuando a Catedral Nossa Senhora de Guadalupe e o Pórtico das Reduções Jesuíticas, que foram concebidos por meio de um projeto que previa sua imagem, os demais templos religiosos se constituíram a partir da comunidade que as idealizou. Mesmo assim, esses espaços podem ser concebidos, na percepção das referências que representam, como os referentes da representação religiosa que os identificam.

Como destacado anteriormente, essa é a principal atratividade ativada pelo turismo. Contudo, os significados, mesmo que discretamente, também podem ser acionados. A opção de reduzir a percepção dos aspectos simbólicos, na sua concepção de imaterialidade, como discretos, se ancora no esforço que se demanda para caracterizar, explicar e fazer compreender os sentidos em torno dos significados de cada referente religioso. Essa questão torna complexo o atrativo e exige uma construção narrativa e discursiva capaz de explicar o ponto de visitação. Essa conclusão novamente nos aproxima da forma com que Llorenç Prats permite perceber uma referência cultural, quando propõe que estes espaços sejam compreendidos como símbolo. Em suas palavras:

La principal virtualidad de um símbolo es su capacidad para expresar de una forma sintética e emocionalmente efectiva una relación entre ideas y valores. Dicho de otra forma, el símbolo tiene la capacidad de transformar las concepciones y creencias en emociones, de encarnarse, y de condensarlas y hacerlas por lo tanto, mucho más intensas. (Prats, 1988, p. 66).

Em outras palavras, os atrativos em análises se enquadram nessa compreensão de símbolo. Ou seja, é narrado e consumido a partir da forma sintética que associa ideias e valores presentes nos respectivos espaços. Mas, nesse sentido, ainda resta apontar os indícios que podem gerar a adesão do visitante ao atrativo, do qual resulta a pergunta: de qual turismo estamos falando?

Uma resposta rápida facilmente pode incorrer em erro de interpretação. Pois, tratando-se de pontos de visitação indicados como religiosos, é de se conjecturar que se compreenda esse turismo como religioso. Contudo, ao tomarmos a definição de turismo religioso como aquele "motivado pela fé ou pelo interesse em alguma cultura religiosa, compreendendo visitas a templos e santuários ou práticas religiosas como peregrinações e romarias" (Jaluska, 2015, p. GT0131), percebe-se que os atrativos não se enquadram nessa situação.

Mesmo que concluamos rapidamente pela definição de não enquadramento ao turismo religioso, é preciso pensar que nem sempre é fácil constituir uma visão definitiva acerca dela. A pergunta provocativa de Emerson 
Silveira é elucidativa dessa situação. Ele questiona: "Turismo religioso, ou simplesmente, aproveitamento turístico de festas, eventos ou lugares religiosos?” (Silveira, 2007, p. 48). Ou como nos lembram Reesink e Reesink (2007), de que se trata de fenômeno complexo, que reside em compreender a dicotomia, nem sempre clara, entre o turista e o romeiro.

Das questões apresentadas, associadas ao nosso objeto, três aspectos chamam atenção: o deslocamento do turista, o consumo e o mercado. A principal atratividade local sem dúvida é a visitação as Cataratas do Iguaçu, que em 18 de dezembro 2018, fechou com o registro 1.788 .923 de turistas, o novo recorde histórico em um ano $(\mathrm{G} 1,2018 \mathrm{~b})$. Ou seja, o consumo e o mercado turístico não têm como foco central de atratividade vinculada às referências culturais da cidade, muito menos ao turismo religioso. Mas, a sua oferta se dá pelas potencialidades paralelas vinculadas a essa forma de turismo. Portanto, essa conclusão nos aproxima do proposto por Ivan Rego Aragão, quando expressa que

[...] nem todo turista é romeiro/peregrino, visto que a visita a lugares e igrejas sagradas pode estar atrelada ao conhecimento cultural, à observação, à curiosidade e, diferentemente das ações constatadas anteriormente, ao usufruto de toda estrutura turística que a cidade/local tem a oferecer. (Aragão, 2014, pp. 60-61)

Mas, é importante ressaltar que esse mercado existe no Brasil e é muito proeminente. Segundo o Instituto Brasileiro de Turismo [EMBRATUR, 2015]

O turismo brasileiro apresenta, a cada ano, números mais expressivos em relação ao segmento religioso. De acordo com dados preliminares do Departamento de Estudos e Pesquisas do Ministério do Turismo, no ano passado, cerca de 17,7 milhões de brasileiros viajaram pelo País levados pela fé. (EMBRATUR, 2015)

Além disso, movimenta valores financeiros significativos, como o apontado pelo jornal O Economista. Segundo o qual "As estimativas oficiais do ministério são de que o segmento movimente cerca de R\$ 15 bilhões por ano no país.” (O Economista, 2015). Portanto, mesmo que esse não seja o foco da exploração do consumo e do mercado turístico local, nos traz indícios das possibilidades associadas a ele.

\section{Considerações Finais}

As análises permitiram compreender que a relação de Foz do Iguaçu com o turismo se constituiu historicamente no decorrer dos últimos 100 anos. Concentra sua atratividade nas Cataratas do Iguaçu, que por décadas se constituiu como o único chamariz. De forma um tanto embrionária, pode-se dizer que visitação a este espaço era contida pelas limitações geográficas, dos meios de transporte e pela pouca amplitude que o turismo lograva na primeira metade do século XX.

Como destacado, essa realidade muda sensivelmente a partir dos anos de 1960, com a ampliação da infraestrutura de transporte que atendia a região, com a inauguração de uma rodovia federal e duas pontes internacionais, uma ligando a cidade de Foz ao Paraguai e outra à Argentina. Nesse mesmo contexto constitui-se o novo aeroporto internacional na cidade. Essas novidades fazem parte do processo histórico do turismo local, mas, por algumas décadas, não resultam em números vultosos como os percebidos a partir da década de 1990.

É preciso dizer que os últimos 30 anos imprimiram profundas mudanças no cenário da região, entre eles o aumento do número de habitantes, o crescimento econômico, a reestruturação e a ampliação do setor hoteleiro, que favoreceram direta ou indiretamente o sucesso do turismo local. Contudo, como destacado, é preciso reconhecer que a profissionalização do turismo, seja pela indução dos poderes públicos, seja pela lógica do mercado, é o aspecto principal na compreensão da consolidação da cidade como um dos principais centros turísticos do Brasil.

Foi dentro desse contexto de massificação turística, associada aos números de visitantes que, progressivamente, se desenvolveu um novo produto turístico na cidade, associado às referências culturais. É 
importante destacar que essa novidade pode ser compreendida dentro de um contexto macro, da elaboração de políticas para a difusão do turismo cultural no Brasil. Assume especificidade o período posterior aos anos de 1980, com a valorização dos potenciais do turismo pautado em referências histórico-culturais, em consonância com o Compromissos de Brasília de 1970, do MEC, com o Compromisso de Salvador de 1971, do IPHAN e a Carta do Turismo Cultural de 1976, do ICOMOS - Conselho Internacional de Monumentos e Sítios.

Se em outras regiões do Brasil esse processo logrou êxitos importantes, como a revitalização do Pelourinho, em Salvador/BA e a revalorização dos centros históricos de Recife/PE, Olinda/PE, Ouro Preto/MG, não foi o que ocorreu na maioria das localidades com esse potencial turístico. Portanto, esta época marca as definições de constituição de políticas públicas com o intuito de fomentar essa exploração econômica.

Em nível local, percebem-se ações que corroboram a dinâmica de valorização das referências culturais no Brasil e no mundo. Em 1990, é publicada a Lei Municipal 1500, que define as diretrizes da preservação do Patrimônio Cultural de Foz do Iguaçu (Foz do Iguaçu, 1990). Será a partir dessa legislação, em consonância às políticas públicas de tentativa de inserir a comunidade local no mercado turístico, por meio da valorização da sua história e cultura, que começam a figurar a divulgação de pontos com potencial para visitação na cidade. Contudo, é preciso lembrar, conforme analisado anteriormente, que os visitantes das Cataratas do Iguaçu sempre se apresentavam como potenciais consumidores de algo mais que pudesse ser oferecido pela cidade ou região. E é neste momento, associado às políticas públicas que, progressivamente, a lógica do mercado constitui um novo recorte turístico na cidade.

As definições do mercado ancoram-se, substancialmente, em levantamentos pré-definidos, pela Secretaria Municipal de Turismo, por meio dos inventários dos pontos histórico-culturais da cidade. Esses serão acionados discursivamente por narrativas epidíticas que procuram enfatizar os elementos que encontram significado e destaque na história local. Assim, consolidam-se representações que sustentam a ativação das referências culturais, pelo turismo, por meio dos referentes e significados associados a elas.

Por fim, como demonstrado, os atrativos religiosos ocupam destaque, pois dos 12 pontos turísticos indicados como histórico-culturais, 5 se relacionam a eles. Um dos indicativos da valorização dessas referências se encontra na possibilidade de valorizar os aspectos materiais e imateriais desses locais de visitação. Eles permitem perceber os referentes arquitetônicos das construções como a ativação dos significados por meio de discursos e narrativas que apresentam ao turista o cenário e os sentidos das referências religiosas destacadas em Foz do Iguaçu.

\section{REFERÊNCIAS}

Aragão, I. R. (2014). Reflexões acerca do turismo cultural-religioso e festa católica no Brasil. Revista Grifos. Chapecó/ SC. 23(36/37), 53-67.

Cardin, E. G. (2010). Expansão do capital e desenvolvimento regional: Foz do Iguaçu entre o legal e o ilegal. Ideação. Foz do Iguaçu, 12(1), 101-117.

Catta, L. E. (2002). O Cotidiano De Uma Fronteira: a perversidade da modernidade. Cascavel - Paraná: Edunioeste. Chartier, R. (1990). História Cultural: entre práticas e representações. Rio de Janeiro: Beltrand Brasil; Lisboa: Difel. De Vaca, A. N. C. (1999). Naufrágios e comentários. São Paulo: L\&PM.

Instituto Brasileiro de Turismo (2015). Turismo religioso em pauta na Embratur. Recuperado em 18 de outubro, 2018 de http://www.embratur.gov.br/piembratur-new/opencms/salaImprensa/noticias/arquivos/Turismo_religios o_em_pauta_na_Embratur.html.

Farias, P. J., \& Monges, F. N. (2006). Memória oral coletiva como forma de exploração do turismo cultural em Foz do Iguaçu com foco no $1^{\circ}$ Campo de Pouso do Município. [Trabalho de Conclusão de Curso de Turismo, Unioeste]. Foz do Iguaçu, Paraná, Brasil. 
Foz do Iguaçu (1990). Lei ordinária 1500 de 24 de setembro de 1990. Recuperado em 15 de fevereiro de 2019 de https://leismunicipais.com.br/a1/pr/f/foz-do-iguacu/lei-ordinaria/1990/150/1500/lei-ordinaria-n-1500-1 990-dispoe-sobre-a-preservacao-do-patrimonio-natural-e-cultural-do-municipio-de-foz-do-iguacu-e-da-outrasprovidencias.

Foz do Iguaçu (2017). Inventário Técnico de Estatísticas Turísticas. Prefeitura Municipal de Foz do Iguaçu - Secretaria Municipal de Turismo.

Foz do Iguaçu (2019a). A cidade. Recuperado em 15 de fevereiro de http://www.pmfi.pr.gov.br/conteudo/\%3Bjsess ionid\%3D0dce3a9b86d3191d7681181f6de7?idMenu=1004.

Foz do Iguaçu (2019b). Histórico-Culturais. Recuperado em 15 de fevereiro de http://www.pmfi.pr.gov.br/turismo $/$ ? idMenu=1233.

G1 (2018a). Parque Nacional do Iguaçu Fecha 2017 com mais de 1,7 milhão de visitantes. Recuperado em 05 de setembro de 2018 de https://g1.globo.com/pr/oeste-sudoeste/noticia/parque-nacional-do-iguacu-fecha-2017com-mais-de-17-milhao-de-visitantes.ghtml.

G1 (2018b). Parque Nacional do Iguaçu bate recorde de visitação anual. Recuperado em 19 de fevereiro de 2019 de https://g1.globo.com/pr/oeste-sudoeste/noticia/2018/12/18/parque-nacional-do-iguacu-bate-recorde-devisitacao-anual.ghtml.

Giménez, G. (2009). Cultura, Identidad y Memoria: materiales para una sociología de los processos culturales en las franjas fronteirizas. Frontera Norte. Tijuana/México, 21(41), 7-32.

Gregory, V. (2012). Obrages nos sertões do Paraná: exploração, trabalho e fronteiras. Ideação. Foz do Iguaçu. 14(1), 43-65.

Henz, A. P., \& Gonçalves, D. (2016). Analise das políticas públicas de fomento para turismo em Foz do Iguaçu. Anais do X Fórum Internacional de Turismo do Iguassu. Foz do Iguaçu, 15 a 17 de junho de 2016.

Instituto Brasileiro de Geografia e Estatística (2010). Censo de 2010. Amostra-Religião. Foz do Iguaçu. Recuperado em 15 de fevereiro de 2019 de https://cidades.ibge.gov.br/brasil/pr/foz-do-iguacu/pesquisa/23/22107?detalh es $=$ true.

Jaluska, T. T. (2015). Turismo religioso em espaços sagrados: possibilidade para a educação patrimonial religiosa. Anais do Congresso ANPTECRE, 05, GT0131.

Krippendort, J. (2009). Sociologia do Turismo: para uma nova compreensão do lazer e das viagens. 3 ed. São Paulo: Aleph.

Loumar Turismo (2019). Passeios em Foz do Iguaçu. Recuperado em 15 de fevereiro de 2019 de https://www.loum arturismo.com.br/passeios-em-foz-do-iguacu/.

Maingueneau, D. (1989). Novas tendências em Análise do Discurso. Campinas, SP: Pontes.

Myskiw, A. M. (2011). A fronteira como destino de viagem: a Colônia Militar de Foz do Iguaçu (1888-1907). Guarapuava: Unicentro/UFF.

O Economista (2015). O turismo religioso movimenta mais de 15 bilhóes por ano na economia brasileira. Recuperado em 18 de dezembro de 2018 de https://www.oeconomista.com.br/turismo-religioso-movimenta-mais-de-r-15bilhoes-por-ano-na-economia-brasileira/.

Oliveira, N. R. O. (2012). Foz do Iguaçu intercultural: cotidiano e narrativas da alteridade. [Dissertação de Mestrado em Sociedade, Cultura e Fronteiras, Unioeste]. Foz do Iguaçu, Paraná, Brasil.

Prats, L. (1988). El concepto del patrimonio cultural. Politica y Sociedad. Madrid, 27, 63-76.

Prats, L. (2005). Concepto e Gestión del Patrimonio Local. Cuadernos de Antropológia Social. Buenos Aires, 21, 17-35.

Reesink, M. L., \& Reesink, E. (2007). Entre Romeiros e Turistas: a busca do turismo religioso como alternativa econômica em um município do sertão baiano. Estudos de Sociologia. Recife, v. 13. n. I, 195-217.

Roseira, A. M. (2006). Foz do Iguaçu: cidade rede sul-americana. Dissertação de Mestrado em Geografia Humana, Universidade de São Paulo. São Paulo, São Paulo, Brasil. 
Santos, O. B, \& Cury, M. J. F. (2015). Segurança Nacional na Tríplice Fronteira entre Argentina, Brasil e Paraguai: Exército Brasileiro. Revista Tempo da Ciência. Toledo/PR, (22)44, 89-99.

Schimmelpfeng, O. (2002). Retrospectos Iguaçuenses. Foz do Iguaçu - Paraná: Editora Tezza.

Silva, R. C. M (2008). Reordenação de identidades de imigrantes árabes em Foz do Iguaçu. Trabalhos em Lingüística Aplicada. Campinas, 47, 357-374.

Silveira, E. J. S. (2007). Turismo Religioso no Brasil: uma perspectiva local e global. Turismo em Análise. São Paulo, $18(1), 33-51$. 